\title{
Origin and timing of Dauphiné twins in quartz cement in fractured sandstones from diagenetic environments: insight from fluid inclusions
}

\author{
András Fall*a, Estibalitz Ukar ${ }^{\mathrm{a}}$, Stephen E. Laubach ${ }^{\mathrm{a}}$
}

June 2016

${ }^{\mathrm{a}}$ Bureau of Economic Geology, Jackson School of Geosciences, The University of Texas at Austin, University Station Box X, Austin, TX 78713-8924, USA

*Corresponding author

E-mail: andras.fall@beg.utexas.edu

Tel: +1 (512) 471-8334; Fax: +1 (512) 471-0140

Submission to Tectonophysics - revised manuscript

\begin{abstract}
Electron backscattered diffraction techniques (EBSD) show that Dauphiné twins in quartz are widespread in many tectonometamorphic environments. Our study documents that under diagenetic temperatures (less than $200^{\circ} \mathrm{C}$ ) and burial depths less than $5 \mathrm{~km}$ Dauphiné twins are common in isolated fracture quartz deposits spanning between fracture walls (i.e., quartz bridges) in low-porosity quartz-cemented sandstones. Using examples from East Texas and Colorado cores, we show that twins are associated with crack-seal microstructure and fluid inclusions. Fracture wall-parallel and wall-normal inclusion trails contain coexisting aqueous and
\end{abstract}


hydrocarbon gas inclusions, so homogenization temperatures of aqueous inclusions record true trapping temperatures. Inclusions in alignments normal to fracture walls are large and irregularly shaped compared to those aligned parallel to walls, but both show similar liquid-to-vapor ratios. Stacking transmitted light images with scanning electron microscope cathodoluminescence (SEM-CL) and EBSD images demonstrates that Dauphiné twin boundaries are localized along wall-normal inclusion trails. Trapping temperatures for wall-normal inclusion trails are usually higher than those aligned parallel to the fracture wall. Wall-normal fluid inclusion assemblage temperatures typically match the highest temperatures of wall-parallel assemblages trapped during sequential widening, but not necessarily the most recent. In context of burial histories for these samples, this temperature pattern implies that wall-normal assemblages form at discrete times during or after crack-seal fracture widening. Localization in isolated, potentially highstress quartz deposits in fractures is compatible with a mechanical origin for these Dauphiné twins. Punctuated temperature values and discrepant sizes and shapes of inclusions in wallnormal trails implies that twinning is a by-product of the formation of the wall-normal inclusion assemblages. The association of Dauphiné twins and fluid inclusion assemblages from which temperature and possibly timing can be inferred provides a way to research timing as well as magnitude of paleostress in some diagenetic settings. (287 words)

\section{Keywords}

Quartz cement bridge; crack-seal; fluid inclusion; Dauphiné twin; fracture; sandstone.

\section{Introduction}

Dauphiné twins in quartz are widespread in a wide range of settings (Ichikawa, 1915; Frondel, 1945; Bragg and Claringbull, 1965; Heidelbach et al., 2000; Barton and Wenk, 2007; 
Winkelmann and Nolze, 2015). This twin law corresponds to a two-fold rotation about the c-axis

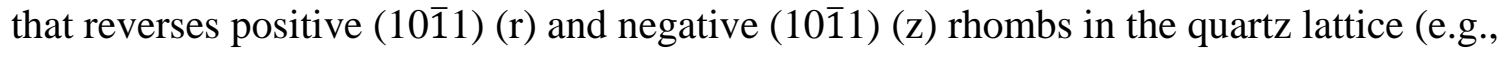
Frondel, 1945; Fig. 1). The boundary is generally irregular. Because orientation of the c-axis is the same in both twin domains, Dauphiné twins are not readily apparent in transmitted light, but rapid identification of Dauphiné twins is feasible by X-ray pole figure goniometry (Baker and Wenk, 1972; Schmid and Casey, 1986), neutron diffraction (Helming et al., 1994), and electron backscattered diffraction techniques (EBSD) (Prior 1999; Prior et al., 1999; Humphreys, 2004; Wright et al., 2015).

Dauphiné twins in $\alpha$ quartz form as primary features during crystal growth (Frondel, 1962; Sunagawa et al., 1990), or as secondary microstructures as a result of deformation (Schubnikow and Zinserling, 1932; Thomas and Wooster, 1951; Barton and Wenk, 2007; Wenk, et al., 2011). Dauphiné twins can form during cooling through the $\alpha-\beta$ transition of hexagonal high-quartz to trigonal low-quartz (at $>573^{\circ} \mathrm{C}$ and ambient pressures), or during rapid cooling between 550-200 $\mathrm{C}$ (Frondel, 1945; van Tendeloo et al., 1976). In low-quartz and in transformation twinning from high- to low-quartz, Dauphiné twins form by local rearrangements of atoms without any larger scale shearing mechanism under differential stress (Zinserling and Schubnikov, 1933; Tullis and Tullis, 1972; Tullis, 1980; Barton and Wenk, 2007; Wenk et al., 2011).

Owing to their sensitivity to non-hydrostatic stress, it is suggested that Dauphiné twins can be used to estimate local paleo-stresses in rocks (e.g., Pehl and Wenk, 2005; Wenk et al., 2006; Wenk et al., 2011; Sintubin and Wenk, 2012; Kjøll et al., 2015). Dauphiné twin paleopiezometers - as well as other measures of past stress states - are most valuable if their time of formation is known. Timing can be inferred if microstructures such as Dauphiné twins 
are localized in folds or fault zones of known age (e.g., Pehl and Wenk, 2005), but in sedimentary rocks that have experienced little or no macroscopic deformation, common structures such as regional opening-mode fracture arrays are notoriously difficult to date, as are any cement deposits and microstructures within them.

In this study we combine scanning electron microscope-based cathodoluminescence (SEM-CL) and electron backscattered diffraction (EBSD) image analysis with fluid inclusion microthermometry to constrain the origin and timing of Dauphiné twins in quartz cement bridges formed in opening mode fractures in tightly cemented sandstones in East Texas and Colorado by addressing the following questions: 1) Were Dauphiné twins in quartz fracture cement formed by mimetic growth on twinned detrital grains, or 2) were they formed by mechanical twinning due to differential stress in already formed bridges?; and 3) if twinning is mechanical did, it occur sometime during fracture opening and cementation, or later when fracture opening and cementation ceased? Quartz cement bridges form as a result of repeated opening and cementation (crack-seal) of natural fractures in sandstone (Laubach, 1988; 2003), process during which fluid inclusions are trapped in trails parallel to the fracture walls (Becker et al., 2010; Fall et al., 2012; 2015). We show that fluid inclusions are also trapped along trails normal to the fracture walls, coincidental with the Dauphiné twin boundaries (DTB). To answer the above questions we test two hypotheses: (1) If the twins are growth twins then fluid inclusions trapped along the twin boundaries should have been trapped with, and have the same homogenization temperature range as the fluid inclusion assemblages (FIAs) in the corresponding crack-seal cements (gap deposits) (Fig. 2a). However, (2) if twins formed due to mechanical effects after crack-seal cementation ceased, fluid inclusions along the DTB should have different homogenization temperatures (Fig. 2b), that correspond to the time when twinning occurred. We 
show that configurations of twins and fluid inclusion assemblages normal to fracture walls are compatible with a mechanical origin for both twins and fracture-wall normal FIAs. An association of FIAs with twin boundaries allows twin formation to be tied to the burial and thermal history of the rocks (Becker et al., 2010), constraining timing and probable loading conditions that led to twinning. Results suggest that twins in partly cemented fractures could be useful paleopiezometers in slightly deformed sedimentary rocks in diagenetic settings.

\section{Geologic setting}

Fracture cement, fluid inclusion and twin observations are from subsurface sandstone units in East Texas and Colorado (Fig. 3). Both settings have been previously studied in detail by Becker et al. (2010) and Fall et al. (2012; 2015). The fractures contain abundant quartz cement bridges (Laubach 1998, 2003) with crack-seal textures that allowed reconstruction of the sequence of fracture opening and cementation, tied to a relatively simple burial history. Samples are from core, thus current temperature and loading conditions are known. Both units have been buried to depths of less than $4 \mathrm{~km}$ and subjected to temperatures in the range of diagenesis $\left(<200^{\circ} \mathrm{C}\right)$ in simple passive margin or foreland basin tectonic settings where the principle structures in nearly flat-lying rocks are steeply dipping regional opening-mode fractures. Dauphiné twins are present in isolated fracture quartz cement deposits that span between fracture walls in otherwise porous opening-mode fractures (Fig. 4).

\subsection{East Texas Basin, Cretaceous Travis Peak Formation}

The Lower Cretaceous Travis Peak Formation ( $600 \mathrm{~m}$ thick), deposited in the gradually subsiding East Texas Basin (Fig. 3a) (Worrall and Snelson, 1989) subsequently experienced regional extension with only minor (<300 m) uplift (Laubach and Jackson, 1990). The formation 
consists of interbedded, mostly very fine- to fine-grained, well-sorted quartz arenite, subarkose, and shale. In the sandstones, extensive quartz cementation has reduced porosity and permeability to typically less than $10 \%$ and $0.1 \mathrm{mD}$ (Dutton and Land, 1988). Locally, partially-open fractures enhance permeability. Fractures dip steeply, perpendicular to bedding, with a predominant strike of ENE. Regionally, fractures parallel regional normal fault trends and the continental margin; the current least principal stress is oriented perpendicular to regional ENE fault trends (Laubach, 1988).

\subsection{Colorado, Cretaceous Iles Formation}

The Upper Cretaceous Iles Formation of the Mesaverde Group was deposited in a Late Cretaceous foreland basin and subsequently experienced regional shortening and uplift during the Paleogene as northwest-southeast-trending asymmetric intermontane basins formed in northwestern Colorado (Fig. 3b) (Johnson and Nuccio, 1986). The sample we studied is from the

Piceance Basin, where maximum depth to base of the Mesaverde Group is more than $4000 \mathrm{~m}$. The Mesaverde Group comprises the Iles and Williams Fork formations, predominantly very fine- to fine- marine and fluvial litharenites (Steel et al., 2012) having low porosity and permeability (e.g. Ozkan et al., 2011, 4-7\% and 0.002-0.003 mD). In the Mesaverde Group, regional fractures are widespread and generally subvertical with WNW- to EW strike (Lorenz and Finley, 1991) and a wide range of aperture sizes up to $\sim 5 \mathrm{~mm}$ (Hooker et al., 2009).

\section{Methods}

Six quartz cement bridges from two different fractures in the Travis Peak Formation (well SFOT1, at depths of $3080.5 \mathrm{~m}$ (10106.85 ft) and $3081.1 \mathrm{~m}$ (10108.3 ft) (Fig. 3), and three bridges from three different fractures in the Iles Formation (well X, depths 2945.53 m (9663.8 
$\mathrm{ft}), 3749.86 \mathrm{~m}$ (12302.7 ft), $3749.95 \mathrm{~m}$ (12303.0 ft) have been analyzed for this study

(Supplementary Table on-line). Although more than half of the observed bridges contain wallnormal FIAs and Dauphiné twins, only the samples mentioned above contain quartz bridges with FIAs large enough in both wall-parallel and wall-normal trails to be suitable for microthermometry. Petrography, SEM-CL analysis, and EBSD mapping were used to document textures and fluid inclusions in quartz deposits in fractures from Travis Peak and Iles formation cores. In both instances regional abundance and size attributes and thermal history of fracture arrays had previously been assessed based on a wider sampling of fractures (Becker et al., 2010; Fall et al., 2012; 2015). Thin sections were cut parallel to bedding and perpendicular to fractures. To avoid thermal damage and resetting of fluid inclusion temperatures in fluid inclusion specimens, samples were analyzed initially for fluid inclusion microthermometry, followed by SEM-CL to document cement textures (gap deposits), and finally EBSD for crystallographic orientation analysis and DTB identification.

Fluid inclusion microthermometry was conducted using a FLUID, Inc.-adapted, U.S. Geological Survey-type, gas-flow heating-freezing stage mounted on an Olympus BX-51 microscope. For each of the 6 bridges studied, 14 to 20 wall-parallel and 1 to 4 wall-normal FIAs have been examined, while the number of inclusions in the FIAs varied from 2 to 12 . Liquidvapor homogenization temperatures were determined to $\pm 0.05^{\circ} \mathrm{C}$ by thermal cycling using temperature steps of $0.1^{\circ} \mathrm{C}$ (Goldstein and Reynolds, 1994). Fluid inclusion homogenization temperatures were sequenced using cross-cutting and overlapping relationships mapped on SEMCL images (Laubach et al., 2004a). Temperature range and trend records were correlated with published burial history curves for each area to specify the time of fracture opening and cementation. 
SEM-CL images were obtained using a Zeiss Sigma High Vacuum Field Emission SEM with an Oxford X-Max 50 Silicon drift detector (SDD) and a Gatan MonoCL4 operated at $5 \mathrm{kV}$. CL images were assembled into contiguous mosaics. Following CL imaging, EBSD maps were obtained with an Oxford Instruments Nordlys detector attached to a Philips XL30 environmental SEM (ESEM). Chemical-mechanical polishing was minimal or avoided to ensure previously measured FIAs were preserved close to the surface of the sample.

EBSD patterns were acquired at low vacuum on rectangular grids by moving the electron beam at regular step sizes between $5 \mu \mathrm{m}$ and $10 \mu \mathrm{m}$, with an electron accelerating voltage of 30 $\mathrm{kV}$, and a working distance of $21.5 \mathrm{~mm}$. Indexing in EBSD maps exceeded 70\%. Most of the failed indexing is due to a large amount of fluid inclusions and associated cavities present at the surface of the samples. EBSD patterns were indexed and post-processed using CHANNEL 5 software (Oxford Instruments, 2007).

\section{Cement microstructures}

\subsection{Quartz deposits}

In sandstones that have experienced deformation at burial temperatures in excess of ca. $80^{\circ} \mathrm{C}$, fractures commonly contain partial quartz cement fill that may be arranged in isolated deposits that span between fracture walls called quartz bridges (Fig. 4). Bridges may be surrounded by porosity or later cement deposits and may be adjacent to areas having thin rinds or veneers of cement (Laubach, 1988; Laubach et al., 2004a). Bridge deposits commonly contain crack-seal microstructure, marking repeated fracture widening and cement precipitation (Fig. 5). Bridges, rinds, and cement deposits that completely fill fractures develop according to the ratio of quartz growth rate to fracture opening rate as described by the Lander and Laubach (2015) 
model for quartz cement growth and sealing in fractures in sandstones. According to this model, rind morphologies develop when the fracture opening rate exceeds two times the fastest rate of quartz growth - along the c-axis on non-euhedral surfaces-because crystals develop slowgrowing euhedral faces. As the ratio of fracture opening to quartz growth rate increases, the proportion of overgrowths that span the fracture decreases and the c-axis orientations for bridging crystals gets progressively closer to perpendicular to the fracture wall until the maximum spanning limit is reached (Lander and Laubach, 2015). Consequently, isolated bridges commonly have their c-axis perpendicular to fracture walls (Ukar et al., 2016).

Bridges are composed of gap deposits that record the crack-seal process and overlapping lateral cements that lack crack-seal texture (Fig. 5c). Crack-seal microstructure results from repeated incremental fracture widening and cementation. Within bridges, paired fracture walls and a gap between the walls marks individual crack opening events. Quartz accumulates syntaxially on these pairs of fracture surfaces, representing the sealing (filling) step of the crackseal process (Fig. 5c). Median lines occur where deposits accreting on facing walls meet along generally sinuous surfaces. Fluid inclusions are trapped along median lines by cement deposits filling gaps created by incremental fracture widening (Fig. 6). For brevity, the combination of sharp, planar fracture walls, paired cement deposits, and median lines with fluid inclusions have been called gap deposits (Laubach et al., 2004b) (Fig. 5). Although all of these features are usually visible in parts of quartz cement bridges, owing to repeated fracturing during bridge development, in many cases only fragments of gap deposits are present. Inclusion-free quartz surrounds the gap deposits, comprising lateral cement deposits that are also concurrent with bridge growth (Lander and Laubach, 2015). These lateral cement deposits form by growth into open void space. Lateral cement growth is slow (Lander and Laubach, 2015); rapid cement 
accumulation is confined to those parts of cement deposits that span between fracture walls subjected to repeated fracture opening.

Within quartz in gap deposits, CL is commonly variable. Although dependent on imaging conditions, inward crystal growth typically produces discontinuous curvilinear luminescence bands parallel and perpendicular to fracture walls (Figs. 5, 7) marking inward free growth of crystals (Laubach, 2003; Fall et al., 2012). At lateral terminations of gap deposits adjacent to lateral deposits, inward-facing paired crystal faces define a sawtooth pattern along the interface between gap and lateral deposits; this pattern results from growth interference of pyramidal quartz faces (Lander and Laubach, 2015, their figure 8).

FIAs trapped in gap deposits by quartz accumulating on fracture surfaces are in trails parallel to fracture walls (Fig. 6). Many bridges also contain other FIAs visible as trails of fluid inclusions aligned at a high angle to fracture walls (Fig. 6). These features were previously not associated with gap deposits, and have hitherto not been accounted for by fracture opening and cement timing models (Becker et al., 2010, Fall et al., 2012; 2015).

In the samples examined, SEM-CL images show that gap thickness perpendicular to fracture walls varies between 1 and $20 \mu \mathrm{m}$ thick. This is a measure of individual crack-seal increment size. Gap deposits differ in length measured parallel to fracture walls. Some are short and are surrounded by thick lateral cement deposits, whereas others cut across the entire bridge width (Fig. 5d). Measured parallel to fracture walls, where gap deposits are longer, lateral cement deposits are narrower, giving the interface of the gap deposit with lateral cement deposits a characteristic serrate pattern (Fig. 5f). This pattern arises because lateral cement accumulates concurrently with crack seal, gradually widening the base of the bridge (Lander and Laubach, 2015). The lateral cement deposits are cut by later fractures within the bridge. As lateral cements 
become wider over time, newly opened fractures and gap deposits cut into preexisting cements extending progressively outwards from the core of the bridge. For geometrically simple bridges (no impingement with adjacent deposits), these differences in gap length are a measure of the age of the gap deposits, with longer gap deposits being younger (Lander and Laubach, 2015). Within each quartz bridge, gap deposits are commonly subparallel to one another, but later fractures cut across earlier deposits, producing complex crosscutting relations (Fig. 7e). By using lengths of gap deposits, or by structural mapping and palinspastic restoration of gap and lateral deposits, the sequence or relative timing of gap deposits can be documented. This procedure also sequences the FIAs contained within gap deposits (Becker et al., 2010; Fall et al., 2010; 2015).

Luminescence variation in gap and lateral cement deposits delineates overlapping and crosscutting relations (Fig. 4c). Some variability in panchromatic images is due to imaging conditions such as dwell time and some to variable CL emission spectra and colors due to trace element and defect structure caused by genetic conditions of quartz precipitation and subsequent deformation (Götze et al., 2001). Our study did not uncover the underlying causes of CL variability in our samples, but shifts in CL character along deposits of a given type or across twin boundaries shows potential for temporal evolution constraints of the crack-seal cementation process and twinning of quartz crystals.

\subsection{Dauphiné twin boundaries}

EBSD imaging reveals widespread Dauphiné twins in quartz bridges in all fractures we analyzed (Fig. 8). Most DTBwithin quartz bridges are irregular where the twinned parts are complexly intergrown and show curviplanar, irregular, globular (on the micron+ scale, depending on crystal size) or as crude three-fold sectoral distributions (Figs. 1, 8). However, in about $10 \%$ of cases DTB are straight (Fig. 8). All these morphologies are in good agreement with 
those described by Frondel (1962). Correlating transmitted light images with SEM-CL and EBSD images in sections cut at a low angle to the c-axis (0001) reveals that in at least 20-30\% of cases DTB are straight and parallel to the c-axis of the quartz bridges. At least in some cases, straight twin boundaries overlap with wall-normal FIAs (Fig. 9). FIA arrangements seen at multiple depths in the thin section in transmitted light images indicate FIAs follow planar surfaces. Based on the correspondence between wall-normal FIAs and straight DTB we infer that at least some straight DTB are planar in the direction parallel to the c-axis of quartz bridges. Given the preferred orientation of quartz bridges with c-axis perpendicular to the fracture wall (Lander and Laubach, 2015; Ukar et al., 2016) straight DTB are thus preferentially oriented at a high angle to fracture walls. Because twin boundaries are orthogonal to the fracture wall they are also perpendicular to wall-parallel gap deposits. In other words, twin boundaries transect crackseal deposits at approximately right angles. DTB are concentrated in the part of the bridge that contains crack-seal textures (i.e., the crack-seal textured core) and copious fluid inclusions.

Some authors have reported a high concentration of Dauphiné twins along detrital grain boundaries (e.g., Zhang et al., 2012). However, such relationships were not observed in the rock or in grain contacts with quartz bridges or between adjacent, impinging quartz bridges, even where crystals of different crystallographic orientations are in contact with one another.

\subsection{Relationships between Dauphiné twin boundaries and luminescence}

Tracing luminescence character along individual gap deposits across twin boundaries reveals marked and abrupt differences in luminescence in some example such as those shown in Figure 7. However, in other cases no shift in luminescence is evident at twin boundaries, such as in the examples in Figure 5. In our small sample suite the case with no luminescence change 
across twin boundaries is slightly more common (Fig. 5). Both cases are found within the same fracture.

In cases where luminescence changes across twin boundaries the variation in luminescence may be subtle but across the twin boundary the brightness of the entire crystal changes (Fig. 7). The bridge in Figure 7 contains two sharp, linear twin planes within the bridge core. The core of the crystal is composed of zones with growth textures and fracture wall-parallel gap deposits that display a complex, curvilinear CL texture. Across the twin boundary on the left of the image, luminescence within both growth-zones and gap deposits becomes generally darker from left to right (Fig. 7e), with an abrupt change at the twin boundary. Across the boundary on the twin on the right luminescence becomes lighter from right to left.

A different pattern is evident where the polarity or symmetry of luminescence patterns shift across the twin boundary. This is shown within a late gap deposit across the same twin boundary in which older gap deposits show a uniform shift in brightness. Gap deposits in Fig. 7e are composed of multiple areas with differing luminescence and internal microstructures. The relatively late gap deposit that cuts across earlier gap deposits is composed of a dark and light sector that are parallel to the walls of the gap deposit. Across the twin boundary on the left of the image, the luminescence of these sectors is reversed; i.e., the light-luminescent sector becomes dark-luminescent and vice versa. This change is less obvious but also present along this late gap deposit on the right of the image. Similar luminescence reversals were observed for some gap deposits, but not others. The presence—or lack—of such relations implies differences in timing of formation of the DTB relative to the gap deposit. 


\section{Fluid inclusion thermometry}

Most of the observed quartz cement bridges in both study areas contain wall-parallel FIA trails, and about half of the observed bridges contain wall-normal FIAs as well (Fig. 6) (Becker et al., 2010; Fall et al; 2012; 2015). For fluid inclusion analyses we selected bridges with wallnormal FIAs that extend all the way to the surface of the cut thin section, for better correlation of the transmitted light and EBSD images.

\subsection{Wall-parallel FIAs in gap deposits}

Multiple fluid inclusions trapped at the same time along a single gap deposit form a primary FIA relative to the gap deposit (Goldstein and Reynolds, 1994). Within an FIA, inclusions are aligned along a planar feature corresponding to the median line of the gap deposit. This planar feature can be observed in the gap deposit when the focus depth is varied on the microscope under transmitted light. In our samples, FIAs are composed of two-phase aqueous liquid-vapor fluid inclusions, most of them coexisting with single-phase hydrocarbon gas inclusions. Aqueous inclusions have elongated, rounded, or negative crystal shapes, and generally have long diameters of less than $\sim 10 \mu \mathrm{m}$, with some reaching sizes of up to $\sim 25 \mu \mathrm{m}$, and containing a vapor bubble of $\sim 10 \mathrm{vol} \%$. Single-phase gas inclusions are somewhat larger (ca. $2 \times$ ), and have a darker rim compared to aqueous inclusions. Most inclusions are oriented with their long dimension parallel to the gap deposit median line.

The samples analyzed in this study show homogenization temperatures $\left(T_{h}\right)$ of aqueous fluid inclusions in gap deposits ranging from $\sim 130{ }^{\circ} \mathrm{C}$ to $\sim 159^{\circ} \mathrm{C}$ in East Texas, and $\mathrm{T}_{\mathrm{h}}$ ranging from $\sim 162{ }^{\circ} \mathrm{C}$ to $176{ }^{\circ} \mathrm{C}$ in the Piceance Basin (Supplementary Table on-line). Temperature variation within any single FIA is generally less than $\sim 3-4{ }^{\circ} \mathrm{C}$, and commonly less than $1{ }^{\circ} \mathrm{C}$. 
In the Travis Peak Formation, final ice melting temperatures of FIAs in similar fractures correspond to salinities of $\sim 15 \mathrm{wt} \% \pm 1 \% \mathrm{NaCl}$ equivalent, and in the Iles Formation to $\sim 2.5$ wt $\% \pm 0.5 \% \mathrm{NaCl}$ equivalent (Becker et al., 2010; Fall et al., 2012; 2015). Single phase hydrocarbon gas inclusions are methane-dominated, with ethane, propane, and $\mathrm{CO}_{2}$ also present (Fall et al., 2012; 2015).

\subsection{Wall-normal FIAs along Dauphiné twin boundaries}

Not all straight DTBs have associated FIAs (Fig. 8), but all wall-normal FIAs found in this study are associated with DTB. Wall-normal FIAs also are aligned along planes, similar to the ones in the gap deposits. The aligned wall-normal inclusions are either primary or pseudosecondary relative to the quartz bridge (Roedder, 1984; Goldstein and Reynolds, 1994). Inclusions in FIAs normal to the fracture wall are 2 to 10 times or more larger than those in gap deposits, and have irregular to negative crystal shapes rather than simple tabular to spherical shapes, but both types show apparently similar liquid-to-vapor ratios. Wall-normal FIAs consist of coexisting aqueous and hydrocarbon gas inclusions, as are those associated with gap deposits. Unlike FIAs in gap deposits, however, CL images do not show that wall-normal FIAs follow continuous quartz-filled fractures.

Wall-normal FIAs have overall $\mathrm{T}_{\mathrm{h}}$ ranging from $\sim 148^{\circ} \mathrm{C}$ to $\sim 158^{\circ} \mathrm{C}$ in East Texas samples, and $163^{\circ} \mathrm{C}$ to $-174^{\circ} \mathrm{C}$ in the Piceance Basin samples (Supplementary Table on-line). The $\mathrm{T}_{\mathrm{h}}$ variation within any single wall-normal FIA is $\left\langle\sim 8{ }^{\circ} \mathrm{C}\right.$ from one side of a bridge to the other, with no systematic temperature variation, despite occurring in configurations transecting gap deposit FIAs that do have systematic variations in temperature across bridges. Temperatures in wall-normal FIAs therefore differ from temperatures of some adjacent gap deposit FIAs, despite being trapped within the same gap deposit. In general, wall-normal FIA temperatures 
correspond with the highest temperature ranges observed in the gap deposits (Fig. 9). For example, the quartz bridge in Figure 9 shows FIAs in gap deposits having temperatures trapped during cement formation that increase from the early range of $135.0^{\circ} \mathrm{C}$ to $138.5^{\circ} \mathrm{C}$ to the later $142.0^{\circ} \mathrm{C}$ to $145.5^{\circ} \mathrm{C}$ and to the latest of $151.0^{\circ} \mathrm{C}$ to $153.0^{\circ} \mathrm{C}$, whereas wall-normal FIAs have temperatures corresponding to the highest and latest gap deposit increments of $151.0^{\circ}$ to 158.5 ${ }^{\circ} \mathrm{C}$. Salinity of the inclusions in both gap deposits and the wall-normal FIAs is $\sim 2.5 \mathrm{wt} \% \mathrm{NaCl}$ equivalent. Thus, while the $T_{h}$ of the gap deposits varies with time, and the $T_{h}$ of the wall-normal FIAs differs from most FIAs in the gap deposits, the composition of the fluid inclusions is similar. The hydrocarbon gas saturation of the aqueous inclusions, and the bulk composition of the hydrocarbon inclusions is also similar, as confirmed by Raman spectroscopic analyses of similar fracture cements (Becker et al., 2010; Fall et al., 2012; 2015).

While temperature sequences between gap deposits increments increase and decrease, wall-normal assemblage temperatures do not necessarily match the latest temperatures in the gap deposits. For example a quartz cement bridge from the Piceance Basin showed wall-normal fluid inclusion $\mathrm{T}_{\mathrm{h}}$ ranging between 171.5 to $175.5^{\circ} \mathrm{C}$, while several gap deposit increments show lower temperature ranges of 162.2 to $168.5^{\circ} \mathrm{C}$. Based on SEM-CL image analysis of the cement texture these lower temperature ranges postdate the highest temperature observed in some early gap deposits and in the wall-normal trails.

\subsection{Light-luminescent halos}

The locations of fluid inclusions trapped along wall-normal FIAs that are near or at the surface of the thin section are visible in secondary electron (SE) and SEM-CL images due to the presence of bright-luminescent domains and halos, some of which surround cavities (Fig. 10). The origin of the difference in luminescence is unknown, but the patterns are suggestive. Locally 
in the center of the light halo are empty topographic depressions formed where fluid inclusions were opened during thin section preparation (Fig. 10). Halos are variably shaped, but most are rhomb-like. In Figure 10b anomalous luminescent areas around fluid inclusions have doubleconcentric halos with an inner light-, a middle dark-, and an outer light-luminescent zone. In some cases, fluid inclusion halos seem to be interconnected and form linear features normal to the fracture walls (Fig. 10b).

\section{Discussion}

\subsection{Wall-parallel fluid inclusions: timing of fracture formation}

Wall-parallel FIAs provide evidence of when fractures formed. Microthermometric and Raman microprobe studies of fluid inclusions trapped in gap deposits during crack-seal growth and sequenced using restoration of gap deposit patterns shows that bridge growth corresponds to systematic changes in trapping temperatures that can be correlated with burial history (Becker et al., 2010; Fall et al., 2012; 2015; Hooker et al., 2015). Coexisting aqueous and hydrocarbon gas inclusions in our samples suggest quartz cement growth and inclusion trapping under immiscible water and methane (hydrocarbon gas) saturated conditions, thus homogenization temperatures of the methane saturated aqueous fluid inclusions represent true trapping temperatures (Roedder, 1984; Goldstein and Reynolds, 1994). FIA temperatures of gap deposits measured in this study correspond with previously assessed samples within the same study areas by Becker et al. (2010) and Fall et al., (2012, 2015). All studies found both increasing and decreasing temperature trends in gap deposits in both East Texas and Piceance samples sequences (Fig. 11). Some samples, however, show little temperature variation, in most cases with temperatures centered on the highest observed temperatures (Fall et al., 2012; 2015). This arises because not all fractures are 
actively widening during the same part of the burial history; in other words, they are not all the same age.

The time of fracture onset and duration can be estimated by correlating fluid inclusion trapping temperature sequences within gap deposits with thermal histories inferred from burial history curves (Hanks et al. 2006; Becker et al. 2010; Fall et al. 2012; 2015; Hooker et al., 2015). Although several assumptions are implicit in this approach, tested results are compatible with other evidence (Lander and Laubach, 2015) in situations where fractures develop bridges. In our East Texas Basin example, trapping temperatures increase from $\sim 130{ }^{\circ} \mathrm{C}$ to $\sim 159{ }^{\circ} \mathrm{C}$, compatible with fracture opening onset at $\sim 49 \mathrm{Ma}$ through $\sim 38 \mathrm{M}$ at $\sim 3080 \mathrm{~m}$, and at $\sim 3081 \mathrm{~m}$ (Fig.11a). In a nearby well, Becker et al. (2010) found a fracture temperature range from $\sim 130^{\circ} \mathrm{C}$ and $\sim 153$ ${ }^{\circ} \mathrm{C}$, and inferred fracture opening from $48 \mathrm{Ma}$ and until close to the present day. These are slow opening rates of 16 to $23 \mu \mathrm{m} / \mathrm{m}$.y.

In the Colorado example, wall-parallel FIA trapping temperatures correlated with burial and thermal history indicates fractures at $\sim 3750 \mathrm{~m}$ in the northern Piceance Basin opened at $\sim 9$ Ma and ceased at $\sim 6 \mathrm{Ma}$ (Fig. 11b). These time estimates are in accordance with the overall fracture opening in this unit estimated to have started at around $40 \mathrm{Ma}$, coinciding with Laramide contraction and corresponding to the fastest burial rates (Fall et al., 2012; 2015).

In both East Texas and Colorado, fracture growth is interpreted to be driven by pore fluid overpressures caused by thermocatalytic gas generation and charge in otherwise structurally quiescent basins (Becker et al., 2010; Fall et al., 2012; 2015). However, similar bridge structures and fluid inclusion sequences can form in the absence of gas charge as a result of tectonic stretching (Hooker et al., 2015). 


\subsection{Wall-normal fluid inclusions: timing and mechanisms of twinning}

Wall-normal FIAs may provide evidence of when twins formed. Fluid inclusion data analyzed in this study indicate fractures did not attain temperatures higher than $\sim 159{ }^{\circ} \mathrm{C}$ in the East Texas Basin and $\sim 180^{\circ} \mathrm{C}$ in the Piceance Basin. These temperatures and cooling rates are well below temperature limits established in the laboratory for transformation Dauphiné twins (Frondel, 1945; van Tendeloo et al., 1976). Thus, under diagenetic conditions twins likely formed either during progressive crystal growth or as a result of concurrent or later mechanical deformation under differential stress (Frondel, 1962).

If the twins are growth twins and the FIAs are contemporaneous then fluid inclusions trapped along the twin boundaries should have been trapped with, and have the same homogenization temperature range as in the corresponding gap deposits (Fig. 2a). However, if twins formed due to mechanical effects after crack-seal cementation ceased, fluid inclusions formed at the same time along the twin boundaries should have different homogenization temperatures (Fig. 2b), that correspond to the time when twinning occurred. FIAs normal to fracture walls have consistent temperatures (within a range of $\sim 4^{\circ} \mathrm{C}$ to $8^{\circ} \mathrm{C}$ ) that differ from the adjacent wall-parallel FIAs. Thus, the latter scenario is most likely.

There is a possibility that the fluid inclusions that follow twin boundaries originally had the same temperatures as the inclusions in the corresponding gap deposits (scenario in Fig. 2a) but were later reequilibrated (Bodnar, 2003) to the highest temperatures during maximum burial. However, this scenario is unlikely because this would trigger reequilibration of all fluid inclusions in both East Texas and Piceance basins, which is not the case. 
The age of the wall-normal fluid inclusions can be inferred from their consistent temperatures and the independently assessed thermal history. In the East Texas samples, temperatures observed in FIAs aligned along twin boundaries normal to fracture walls range from $\sim 148{ }^{\circ} \mathrm{C}$ to $\sim 158^{\circ}$, and in the Piceance Basin samples $\sim 163{ }^{\circ} \mathrm{C}$ to $\sim 174{ }^{\circ} \mathrm{C}$. These ranges correspond to the highest temperatures in each samples. Timing constraints by correlating inclusion temperatures with thermal evolution models imply that wall-normal fluid inclusions in the East Texas Basin formed at $\sim 40 \mathrm{Ma}$, and in the Piceance Basin at $\sim 8 \mathrm{Ma}$ (Fig. 11). That the wall-normal fluid inclusion assemblages formed at a specific and discrete time in the long history of these fractures suggests that they reflect a specific event.

This timing could indicate 1) the time of twinning and associated FIA entrapment, or 2) the time of wall-normal FIA entrapment along which DTBs nucleated at a later event. All wallnormal FIAs correspond to twin boundaries, but not all straight twin boundaries have visible FIAs. Although twin boundaries lacking visible wall-normal FIAs might have FIAs composed of inclusions too small to be visible, the fact that wall-normal inclusions tend to be larger than other inclusions in the bridges argues against wall-normal FIAs being missed. Thus we infer that straight twin boundaries perpendicular to fracture walls can exist without wall-normal FIAs indicating that the timing of FIA entrapment corresponds with the twining. Thus, the timing of twinning in East Texas Basin probably occurred at $\sim 40 \mathrm{Ma}$, and in the Piceance Basin at $\sim 8 \mathrm{Ma}$ (Fig. 11).

The temporal and thermal evidence obtained from fluid inclusions points to a mechanical origin of Dauphiné twins in the quartz cement bridges. Mechanical Dauphiné twins are stressdependent features that arise as a result of loading and the crystallographic orientation of quartz with respect to the stress field. The driving force for mechanical twinning under constant stress is 
minimization of internal energy of the system acting to maximize the elastic strain energy of the crystal (Tullis and Tullis, 1972). The DTB were formed in quartz bridges that are connecting to the fracture walls through an isolated small-footprint in fractures that are under load, creating potentially high stress settings. In a relaxed state (fractures not actively opening), such bridges could be under load, or high stress, that could trigger twinning. However, the load could not be too high, as in both rock units there are open fractures where bridges are present. Moreover, there is no evidence to the presence of widespread axial splitting fractures within the narrow and delicate bridges. This could be a result of either slow, mild compression between episodes of fracture widening, or low stress applied to the bridge during relaxation. Experimental studies show that Dauphiné twins in quartz could be formed at stresses as low as $0.9 \mathrm{~kb}$ (Laughner et al., 1979). Moreover, pressure fluctuations due to hydrocarbon gas generation are suggested to be the driving mechanism of the fracture opening. The repeated process of overpressuring and fracturing is reflected in the gap deposit increments, with episodes of fracture relaxation implied between the formation of subsequent crack-seal episodes, as evidenced from fluid inclusion observations (Becker et al., 2010; Fall et al., 2012; 2015). All these observations establish that a mechanical driver for twin formation is plausible in quartz cements in these settings.

Unlike twinning laws in other minerals such as calcite and feldspar, in Dauphiné twins no bonds are broken between $\mathrm{Si}-\mathrm{O}$ atoms and no permanent macroscopic strain is accommodated by the crystal along the twins (Frondel, 1962; Tullis and Tullis, 1972; Tullis, 1980). If no bonds are broken along twin boundaries, then the mechanism by which fluid inclusions and mechanical twin boundaries form requires an explanation.

SEM-CL images reveal no visible continuous cemented fractures along the fracture-wallnormal assemblages, such as those along the gap deposits. The inclusions in the wall-normal 
assemblages are irregularly shaped, larger than the inclusions in the gap deposits, and in some cases they are larger than the individual gap deposit sizes (widths). The presence of larger fluid inclusions, having consistent liquid-to-vapor ratios, temperatures, and fluid composition along these assemblages, as well as presence of the bright-luminescent cement surrounding them (halos), is compatible with formation of the inclusions after those in the gap deposits.

To form the fluid inclusions and associated surrounding halos fluid communication is needed between the inclusions. The relatively large size of twin boundary-parallel, wall-normal fluid inclusions and bright-luminescent cement haloes (Figs. 10, 12 and 13) suggests transport of new fluid along the inclusions trapped along the twin boundaries. These inclusions probably formed in the quartz cement bridge along crystal defects or reentrants enclosed by the crystal faces of precipitating quartz gap deposits (Fig. 12a, b). The reentrants are aligned in crystallographic continuity across gap deposits throughout the quartz cement bridge, and as a consequence the fluid inclusions were aligned in the subsequent gap deposits (Fig. 12b, c, d). Thin quartz walls between the aligned large inclusions could have been broken due to stress increase applied during fracture relaxation and twinning (Fig. 13). This process could have resulted in the formation of partial channels by connecting the aligned inclusions, allowing flow of aqueous fluids and entrapment of large, wall-normal fluid inclusions around which bright luminescent cement (halos) precipitated in preexisting inclusion cavities (Fig. 12e, 13). This is supported by the fact that some of the bright-luminescent cement halos appear to be continuous across subsequent gap deposits (Fig. 10). This suggests that some (if not all) of the halos are connected, and some are out of the plane of the imaged thin section, as illustrated in Figure 13, and the apparent discontinuity of bright-luminescent cement in the image is a thin section cutting effect. 
Another possibility is that fluid diffused through the crystal lattice and accumulated to form inclusions or reequilibrateed preexisting fluid inclusions in the gap deposits. DTB have been recognized to exert an important role in the distribution of intracrystalline plastic deformation and act as preferred sites of dynamic recrystallization (Stipp and Kunze, 2008; Menegon et al., 2011; Kjøll et al., 2015). Thus, lattice defects aligned preferentially along these twin boundaries could act as concentration sites for diffused fluid. The fluid inclusions would have been then reequilibrated under the pressure $(\mathrm{P})$ and temperature $(\mathrm{T})$ conditions at which mechanical twins formed (Bodnar, 2003). However, fluid diffusion into and out of the fluid inclusions is insignificant at these low temperature and pressure conditions (Qin et al., 1992; Bakker, 2009). If no new quartz is deposited around the inclusions in wall-normal trails the contrasting cement luminescence of the halos could be the result of composition or microstructural (defect) alteration of quartz surrounding the inclusions, similar to the process described by Lambrecht and Diamond (2014) in metamorphic quartz veins. However, this process of morphological ripening, resulting in purification (trace element depletion) by coupled dissolution and reprecipitation of quartz surrounding the fluid inclusion produces dull, nonluminescent halos in quartz (Lambrecht and Diamond, 2014). Therefore, we consider such scenario to be unlikely.

An alternative possibility is that fluid inclusions apparently trapped along twin boundaries are preexisting fluid inclusions in gap deposit trapped at the $\mathrm{P}$ and $\mathrm{T}$ conditions at which the respective gap deposits formed (Fig. 2a), then acted as substrate for twin nucleation during which they reequilibrated to the new $\mathrm{P}$ and $\mathrm{T}$ conditions present during twinning. DTBs are known to be localized along crystal defects and irregularities such as solid inclusions (Frondel, 1962). Therefore, preexisting fluid inclusions along gap deposits could have acted as 
nucleation sites for the twins. However, wall-normal fluid inclusions are larger than gap deposit inclusions, but the liquid to vapor ratio within both types of FIAs is apparently similar. If preexisting inclusions were stretched to a larger volume and reequilibrated to new P-T conditions, the liquid to vapor ratio of the new inclusions would be lower than in the primary fluid inclusion (i.e., a larger bubble would be surrounded by a thinner veneer of liquid in the reequilibrated inclusion), which is not seen. Furthermore, the fact that some wall-normal, straight Dauphiné twin boundaries can exist without associated FIAs in both basins suggests that twin boundaries can form without fluid inclusions acting as substrate for twin nucleation, validating the inference that Dauphiné twining and wall-normal FIA formation is most likely coeval.

Based on this timing, Dauphiné twining occurred coinciding with maximum burial in the East Texas Basin, whereas, in the Piceance Basin twinning occurred during uplift. Fracture opening and cementation of gap deposits in The Piceance example must have continued after the formation of the Dauphiné twins (Fig. 11). Wall-normal FIAs do not cut across the younger parts of the bridges that we studied, but Dauphiné twins continue across indicating that posterior growth of quartz must have mimicked the orientation of the mechanical twin.

Mechanical Dauphiné twins may be used as a paleopiezometer (e.g., Pehl and Wenk, 2005; Wenk et al., 2006). However, identifying timing and mechanism of twin formation increases the usefulness of Dauphiné twins. Our study shows that in quartz cement deposits formed concurrently with fracture opening, combining SEM-CL and EBSD imaging with fluid inclusion microthermometry can be used to shed light on the syn- and post-formation loading history of fractures. 


\section{Summary and Conclusions}

In quartz fracture cements that show synkinematic crack-seal textures, electron backscattered diffraction imaging (EBSD) shows that Dauphiné twins are widespread. Our study shows that in sandstones buried to depths of as much as $5 \mathrm{~km}$ and temperatures of as much as $\sim 180^{\circ} \mathrm{C}$, twins occur in isolated quartz cement deposits that span between fracture walls. In fractures we studied, twin boundaries are aligned normal to fracture walls, a configuration compatible with mechanical twinning caused by loads on the isolated quartz deposits.

In fractures in cores from East Texas and Colorado, fluid inclusions in quartz deposits provide evidence of when twins formed relative to fracture opening. We reconstructed fracture opening history by mapping crack-seal texture illuminated by SEM-CL images. Fluid inclusion assemblages trapped during progressive opening in gap deposits and sequenced by texture mapping allows the fracture thermal history to be compared to that derived from the burial history of the formations, allowing the duration of fracture opening to be estimated. Correlating transmitted light, SEM-CL, and EBSD images reveals trails of fluid inclusions aligned normal to the fracture walls coincide with DTB. The fluid inclusion evidence also constrains when Dauphiné twins formed. Correlating inclusion trapping temperatures with the burial history indicates that twinning occurred during maximum burial at $\sim 40$ Ma in the East Texas samples, and $\sim 8 \mathrm{Ma}$ in the Colorado samples.

Wall-normal FIAs trapped along DTBs have trapping temperatures that differ from those of FIAs aligned parallel to fracture walls and trapped sequentially during fracture widening. Wall-normal FIAs in most cases have high temperatures that correspond to those of the wallparallel assemblages trapped during the highest temperature sequential widening. This 
temperature pattern implies that wall-normal assemblages mostly postdate crack-seal fracture widening. This temperature pattern along with co-location of twin boundaries and assemblages implies a mechanical origin for these Dauphiné twins. Results show that twinned fracture quartz deposits are potentially valuable sources of information on the loading history of fractures.

\section{Acknowledgments}

This study was funded by grant DE-FG02-03ER15430 from Chemical Sciences, Geosciences and Biosciences Division, Office of Basic Energy Sciences, Office of Science, U.S. Department of Energy and by the Fracture Research and Application Consortium. Some elements of this work benefited from the ExxonMobil-Bureau of Economic Geology (UT Austin) Collaborative Study on Unconventional Reservoirs. Scanning electron microscope analyses were in part funded by a Jackson School of Geosciences seed grand and a GDL Foundation Fellowship. We thank Matthew Steele-MacInnis and an anonymous reviewer for their thoughtful and constructive reviews that significantly contributed to the improvement of the manuscript. Publication authorized by the Director, Bureau of Economic Geology, The University of Texas at Austin.

\section{REFERENCES}

Baker, D.W., Wenk, H.-R., 1972. Preferred orientation in a low-symmetry quartz mylonite: Journal of Geology 80, 81-105.

Bakker, R.J., 2009. Reequilibration of fluid inclusions: bulk diffusion. Lithos 112, 277-288.

Barton, N. R., Wenk, H. R., 2007. Dauphiné twinning in polycrystalline quartz. Modelling and Simulation in Materials Science and Engineering 15, 369. 
Becker, S.P., Eichhubl, P. Laubach, S.E., Reed, R.M., Lander, R.H., Bodnar, R.J., 2010. A 48 m.y. history of fracture opening, temperature, and fluid pressure: Cretaceous Travis Peak Formation, East Texas Basin. GSA Bull. 122, 1081-1093.

Bodnar, R.J., 2003. Re-equilibration of fluid inclusions, In: Samson, I., Anderson, A., Marshall, D. (Eds.), Fluid Inclusions: Analysis and Interpretation, Mineralogical Association of Canada Short Course 32, 213-231.

Bragg L. and Claringbull, G. F., 1965. Crystal Structures of Minerals. Bell, London, Vol. IV.

Dutton, S. P., Land, L. S. 1988. Cementation and burial history of a low-permeability quartzarenite, Lower Cretaceous Travis Peak Formation, East Texas. GSA Bull. 100, 12711282.

Fall, A., Eichhubl, P., Bodnar, R. J., Laubach, S. E., Davis, J. S., 2015. Natural hydraulic fracturing of tight-gas sandstone reservoirs, Piceance Basin, Colorado. GSA Bull. 127, 6175.

Fall, A., Eichhubl, P., Cumella, S.P., Bodnar, R.J., Laubach, S.E., Becker, S.P., 2012. Testing the basin-centered gas accumulation model using fluid inclusion observations: southern Piceance Basin, Colorado. AAPG Bull. 96, 2297-2318.

Frondel, C., 1945. Secondary Dauphine twinning in quartz. Am. Mineral. 30, 447-461.

Frondel, C., 1962. The system of mineralogy. $7^{\text {th }}$ edn., vol 3. Wiley, New York.

Götze, J., Plötze, M., Habermann, D., 2001. Origin, spectral characteristics and practical applications of the cathodoluminescence (CL) of quartz-a review. Mineral. Petrol. 71, 225250. 
Goldstein, R. H., Reynolds, T. J., 1994. Systematics of fluid inclusions in diagenetic minerals: Society for Sedimentary Geology Short Course 31, SEPM (Society for Sedimentary Geology), Tulsa, Oklahoma, 199 p.

Hanks, C.L., Parris, T.M., Wallace, W.K., 2006. Fracture paragenesis and microthermometry in Lisburne Group detachment folds: Implications for the thermal and structural evolution of the northeastern Brooks Range, Alaska. AAPG Bull. 90, 1-20.

Heidelbach, F., Kunze, K., Wenk, H.-R., 2000. Texture analysis of a recrystallized quartzite using electron diffraction in the scanning electron microscope. J. Struct. Geol. 22, 91-104.

Helming, K., Schwarzer, R., Rauschenbach, B., Geier, S., Wenk, H.-R., Ullemaier, K. Heinitz, J., 1994. Texture estimates by means of components. Z. Metallk. 85, 545-553.

Hooker, J.N., Gale, J.F.W., Gomez, L.A., Laubach, S.E., Marrett, R., Reed, R.M., 2009. Aperture-size scaling variations in a low-strain opening-mode fracture set, Cozzette Sandstone, Colorado. J. Struct. Geol. 31, 707-718.

Hooker, J.N., Larson, T., Eakin, A., Laubach, S.E., Eichhubl, P., Fall, A., Marrett, R., 2015. Fracturing and fluid-flow in a sub-décollement sandstone; or, a leak in the basement. J. Geol. Soc., London 72, 428-442.

Humphreys, F.J., 2004. Characterisation of fine-scale microstructures by electron backscatter diffraction (EBSD). Script. Mater. 51, 771-776.

Ichikawa, S., 1915. Studies of the etched figures of Japanese quartz; Am. J. Sci., XXVIII Series $4,39,455-473$. 
Johnson, R.C., Nuccio, V.F., 1986. Structural and Thermal history of the Piceance Creek Basin, western Colorado, in relation to hydrocarbon occurrence in the Mesaverde Group: in Spencer, C.W., and Mast, R.F., eds., Geology of Tight Gas Reservoirs: AAPG Studies in Geology 24, 165-205.

Kjøll, H.J. Viola, G., Menegon, L., Sørensen, B.E., 2015. Brittle-viscous deformation of vein quartz under fluid-rich lower greenschist facies conditions. Solid Earth 6, 681-699.

Lambrecht, G., Diamond, L.W., 2014. Morphological ripening of fluid inclusions and coupled zone-rifting in quartz crystals revealed by cathodoluminescence imaging: implications for CL-petrography, fluid inclusion analysis, and trace element geothermometry. Geochim. Cosmochim. Acta 141, 381-406.

Lander R.H., Laubach, S.E. 2015. Insights into rates of fracture growth and sealing from a model for quartz cementation in fractured sandstones. GSA Bull. 127, 516-538.

Laubach, S.E., 1988. Subsurface fractures and their relationship to stress history in East Texas Basin sandstone: Tectonophys. 156, 37-49.

Laubach, S.E., 2003. Practical approaches to identifying sealed and open fractures. AAPG Bull. $87,561-579$.

Laubach, S.E., Jackson, M.L.W., 1990. Origin of arches in the northwestern Gulf of Mexico basin. Geology 18, 595-598.

Laubach, S.E., Reed, R.M., Olson, J.E., Lander, R. H., Bonnell, L.M., 2004a. Coevolution of crack-seal texture and fracture porosity in sedimentary rocks: cathodoluminescence observations of regional fractures. J. Struct. Geol. 26, 967-982. 
Laubach, S., Lander, R., Bonnell, L., Olson, J., Reed, R., 2004b. Opening histories of fractures in sandstone: in Cosgrove, J.W., Engelder, T., editors, The initiation, propagation, and arrest of joints and other fractures, Geol. Soc. London Spec. Publ. 231, 1-9.

Laughner, J.W., Cline, T.W., Newnham, R.E., Cross, L.E., 1979. Acoustic emissions from stress-induced Dauphine' twinning in quartz. Phys. Chem. Min. 4, 129-137.

Lorenz, J. C., Finley, S.J. 1991. Regional Fractures II: Fracturing of Mesaverde Reservoirs in the Piceance Basin, Colorado. AAPG Bull. 75, 1738-1757.

Menegon, L., Piazolo, S., Pennachioni, G., 2011. The effect of Dauphiné twinning on plastic strain in quartz. Contrib. Mineral. Petrol. 161, 635-652.

Oxford Instruments, 2007. HKL Technology CHANNEL 5 user manual, 475 p.

Ozkan, A. Cumella, S.P., Milliken, K.L. Laubach, S.E., 2011. Prediction of lithofacies and reservoir quality using well logs, Williams Fork Formation, Mamm Creek Field, Piceance Basin. AAPG Bull. 95, 1699-1723.

Pehl, J., Wenk, H.R., 2005. Evidence for regional Dauphiné twinning in quartz from the Santa Rosa mylonite zone in Southern California. A neutron diffraction study. J. Struct. Geol. 27, 1741-1749.

Prior, D.J., 1999. Problems in determining misorientation axes, for small angular misorientations, using electron backscatter diffraction in the SEM. J. Microscopy 195, 217225.

Prior, D.J., Boyle, A.P., Brenker, F., Cheadle, M.C., Day, A., Lopez, G., Peruzzo, L., Potts, G.J., Reddy, S., Spiess, R., Timms, N.E., Trimby, P., Wheeler, J., Zetterstrom, L., 1999. The 
application of electron backscatter diffraction and orientation contrast imaging in the SEM to textural problems in rocks. Amer. Mineral. 84, 1741-1759.

Qin, Z., Lu, F., Anderson A.T., Jr., 1992. Diffusive reequilibration of melt and fluid inclusions. Amer. Mineral. 77, 565-576.

Roedder, E., 1984. Fluid Inclusions. Mineralogical Society of America, Washigton, D.C., 644 p.

Schmid, S.M., Casey, M., 1986. In: Complete fabric analysis of some commonly observed quartz C-axis patterns. American Geophysical Union Geophysical Monograph 36, 263-286.

Schubnikow, A., Zinserling, K., 1932. Über die Schlag- und Druckfiguren und über die mechanischen Quarzzwillinge. Z Kristallogr. 83, 243-264.

Sintubin, M., Wenk, H.R., 2012. Looking at Dauphiné twins in vein quartz from the HighArdenne slate belt as a potential paleostress indicator. AGU Fall Meeting Abstracts 1, 2468.

Steel, R.J., Plink-Bjorklund, P., Aschoff, J., 2012. Tidal deposits of the Campanian Western Interior Seaway, Wyoming, Utah and Colorado, USA. In Principles of Tidal Sedimentology, Springer Netherlands. 437-472.

Stipp, M., Kunze, K., 2008. Dynamic recrystallization near the brittle-plastic transition in naturally and experimentally deformed quartz aggregates. Tectonophys. 448, 77-97.

Sunagawa, I., Taijing, L., Balitsky, V.S., 1990. Generation of Brazil and Dauphiné twins in synthetic amethysts. Phys. Chem. Mineral. 17, 320-325.

Thomas L.A., Wooster W.A., 1951. Piezocrescense - the growth of Dauphiné twinning in quartz under stress. Proc. R. Soc. Lond. Ser. A 208, 43-62. 
Tullis T.E., 1980. The use of mechanical twinning in minerals as a measure of shear stress magnitudes. J. Geophys. Res. 85, 6263-6268.

Tullis, J., Tullis, T.E., 1972. Preferred orientation produced by mechanical Dauphiné twinning. Thermodynamics and axial experiments. AGU. Monogr. 16, 67-82.

Ukar, E., Laubach, S. E., and Marrett, R., 2016, Quartz c-axis orientation patterns in fracture cement as a measure of fracture opening rate and a validation tool for fracture pattern models. Geosphere 12, 400-438.

van Tendeloo, G., Van Landuyt, J., Amelinckx, S., 1976. The $\alpha \rightarrow \beta$ phase transition in quartz and AlPO4 as studied by electron microscopy and diffraction. Physica Status Aolidi 33, 723735.

Wenk, H.R., Rybacki, E., Dresen, G., Lonardelli, I., Barton, N., Franz, H., Gonzalez, G., 2006. Dauphiné twinning and texture memory in polycrystalline quartz. Part 1: experimental deformation of novaculite. Phys. Chem. Mineral. 33, 667-676.

Wenk, H.R., Janssen, C., Kenkmann, T., Dresen G., 2011. Mechanical twinning in quartz: shock experiments, impact, pseudotachylites and fault breccias. Tectonophys. 510, 69-79.

Winkelmann, A., Nolze, G., 2015. Chirality determination of quartz crystals using Electron Backscatter Diffraction. Ultramicroscopy 149, 58-63.

Worrall, D.M., Snelson, S., 1989. Evolution of the northern Gulf of Mexico. The geology of North America; an overview. GSA, Geology of North America, v. A, 97-138.

Wright, S.I., Nowell, M.M., de Kloe, R., Camus, P., Rampton, T., 2015. Electron imaging with an EBSD detector. Ultramicroscopy 148, 132-145. 
Yurewicz, D.A., Bohacs, K.M., Kendall, R.E., Kronmueller, K., Maurer, M.E., Ryan, T.C., Yeakel, J.D., 2008. Controls on gas and water distribution, Mesaverde basin-centered gas play, Piceance Basin, Colorado. In: Cumella, S.P., Shanley, K.W., Camp, W.K. (Eds.), Understanding, exploring, and developing tight-gas sands - 2005 Vail Hedberg Conference. AAPG Hedberg Ser. 3, 105-136.

Zhang, B., Zhang, J., Yan, S., Gu, Z., Wang, X., 2012. Detrital quartz and quartz cement in upper Triassic reservoir sandstones of the Sichuan basin: characteristics and mechanisms of formation based on cathodoluminescence and electron back-scatter diffraction analysis. Sediment. Geol. 267-268, 104-114.

Zinserling, K., and Schubnikov, A., 1933. Uber die Plastizität des Quarzes. Zeitschrift für Kristallographie 85, 454-461. 


\section{Supplementary Table - on-line.}

Ranges of homogenization temperatures $\left(T_{h}\right)$ of aqueous fluid inclusions in fracture-wall-parallel and wall-normal fluid inclusion assemblages (FIA) in quartz-filled fractures in sandstones of the East Texas and Piceance Basins. 
Figures with captions
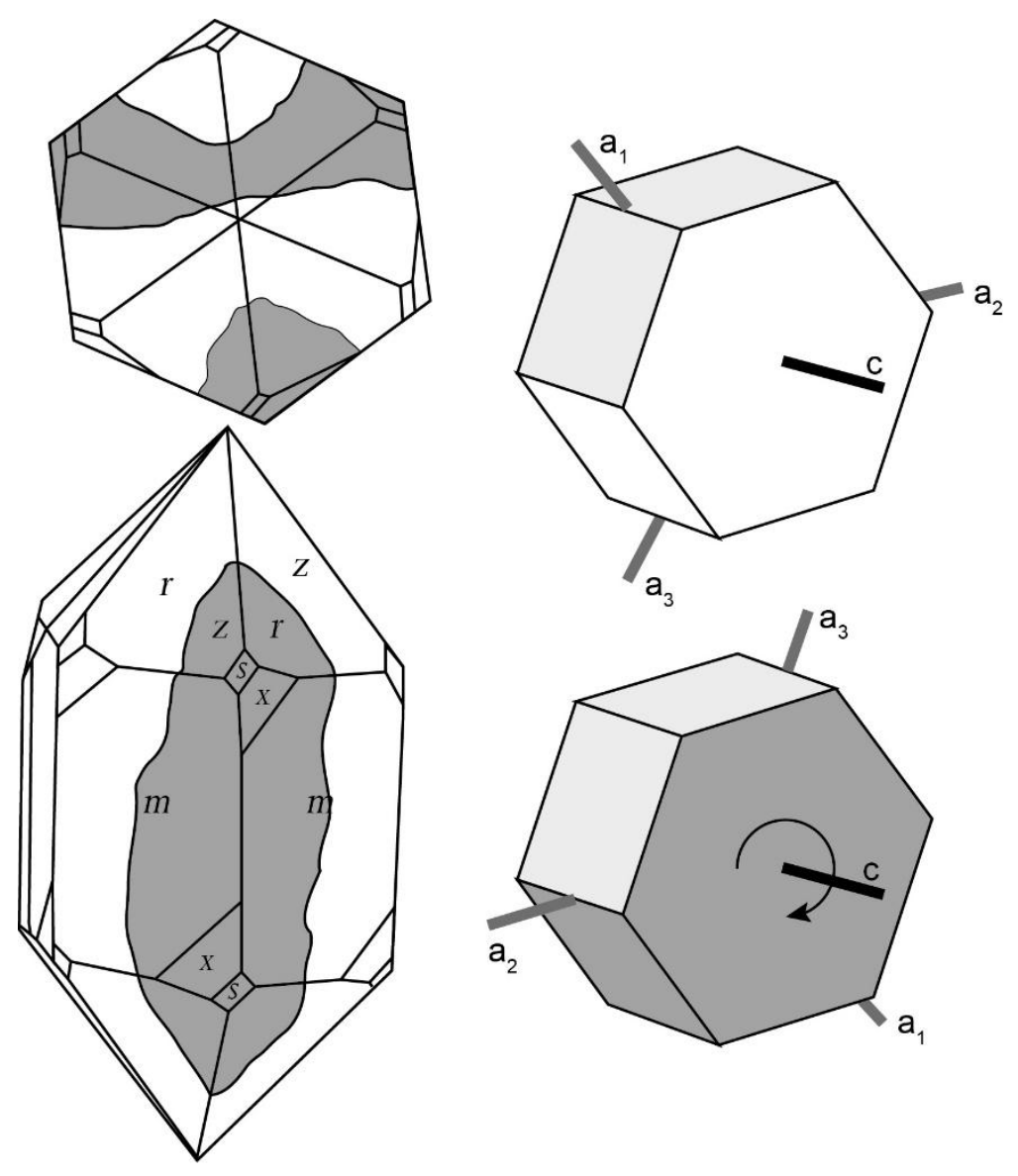

Figure 1.

Fig. 1. Sketch of interpenetrated Dauphiné twins that are related geometrically by a rotation of $180^{\circ}$ about the c-axis of quartz crystals (modified after Frondel, 1945). Gray areas show the twinned domains of the quartz crystal. 

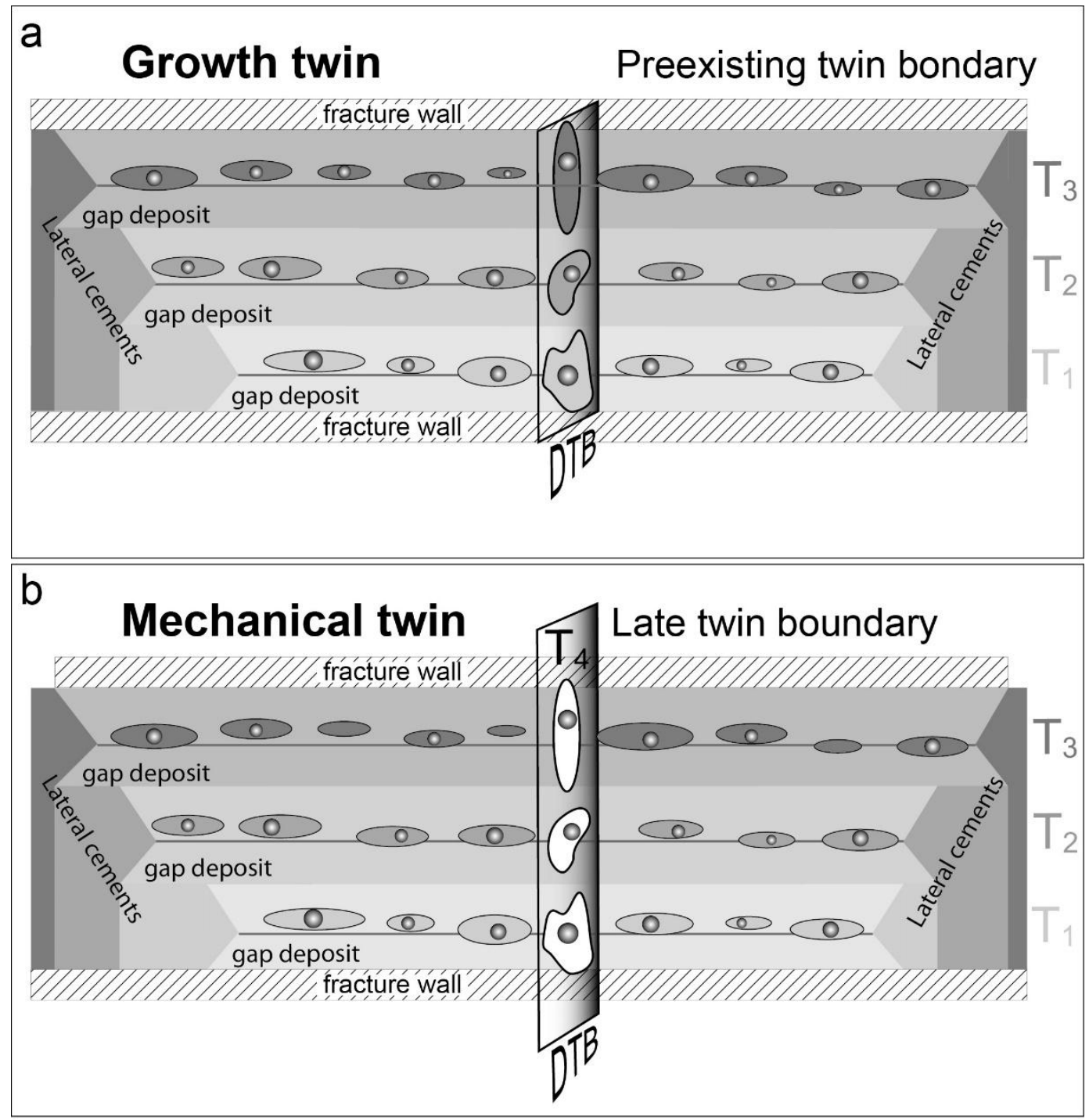

Figure 2.

Fig. 2. Cement deposit configurations and fluid inclusion assemblage patterns within quartz bridges. Gap deposits (horizontal bands) and lateral cements are progressively younger toward the top of the diagrams based on overlap relations. These features are visible in SEM-CL. FIAs $\mathrm{T}_{1-3}$ in this example show progressively younger trapping temperatures; timing is from the mapped sequence of gap deposits. $\mathrm{T}_{4}$ and DTB mark the observed locations of wall-normal FIAs and Dauphiné twin boundary relative to gap deposits and fracture walls. Expected patterns of $\mathrm{T}_{4}$ 
fluid inclusion attributes are shown for (a) growth versus (b) mechanical Dauphiné twin models, as elaborated in the Introduction and Discussion. 

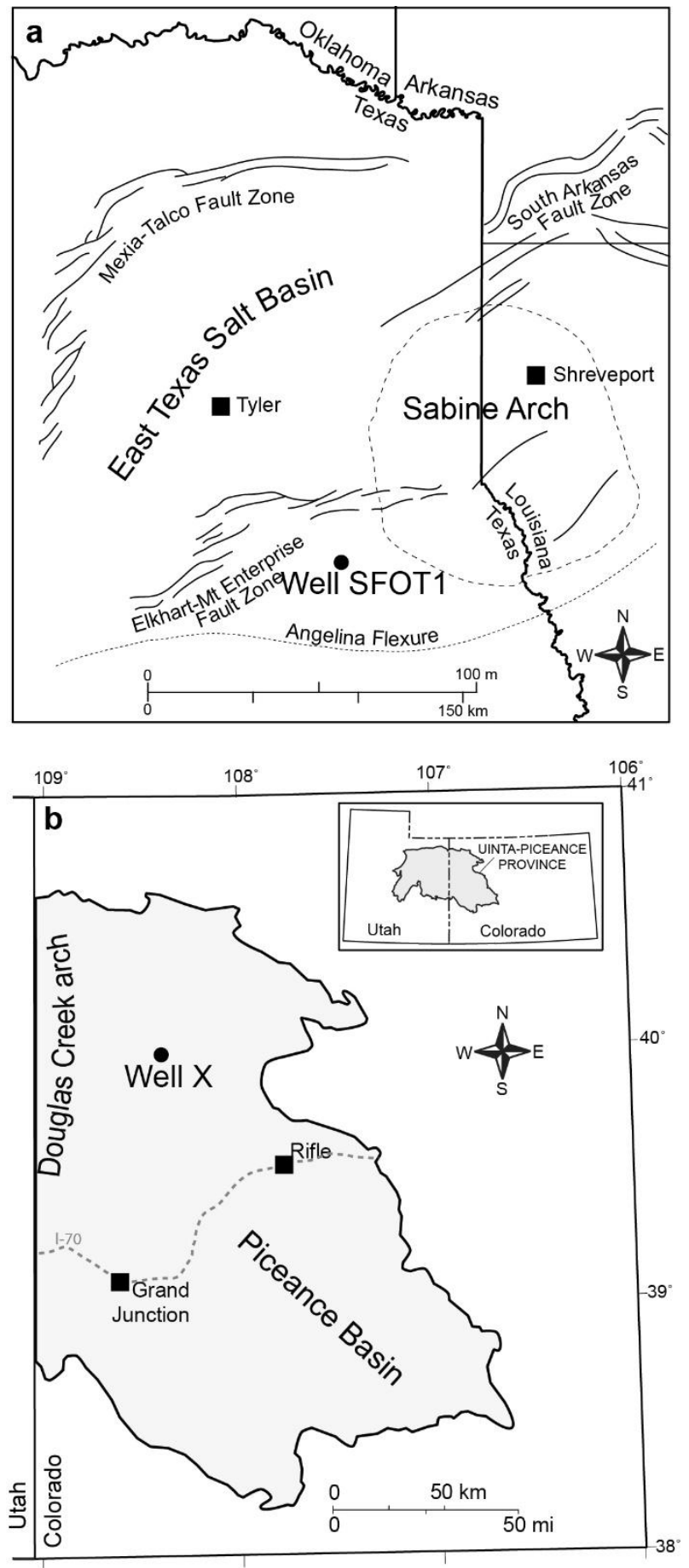

Figure 3. 
Fig. 3. Location maps of (a) East Texas Basin (modified after Becker et al., 2010), and (b)

Piceance Basin, Colorado (modified after Yurewicz et al., 2008), showing location of wells from which core samples SFOT1, and Well X, respectively, were obtained. Data shown in Supplementary Table on-line. 

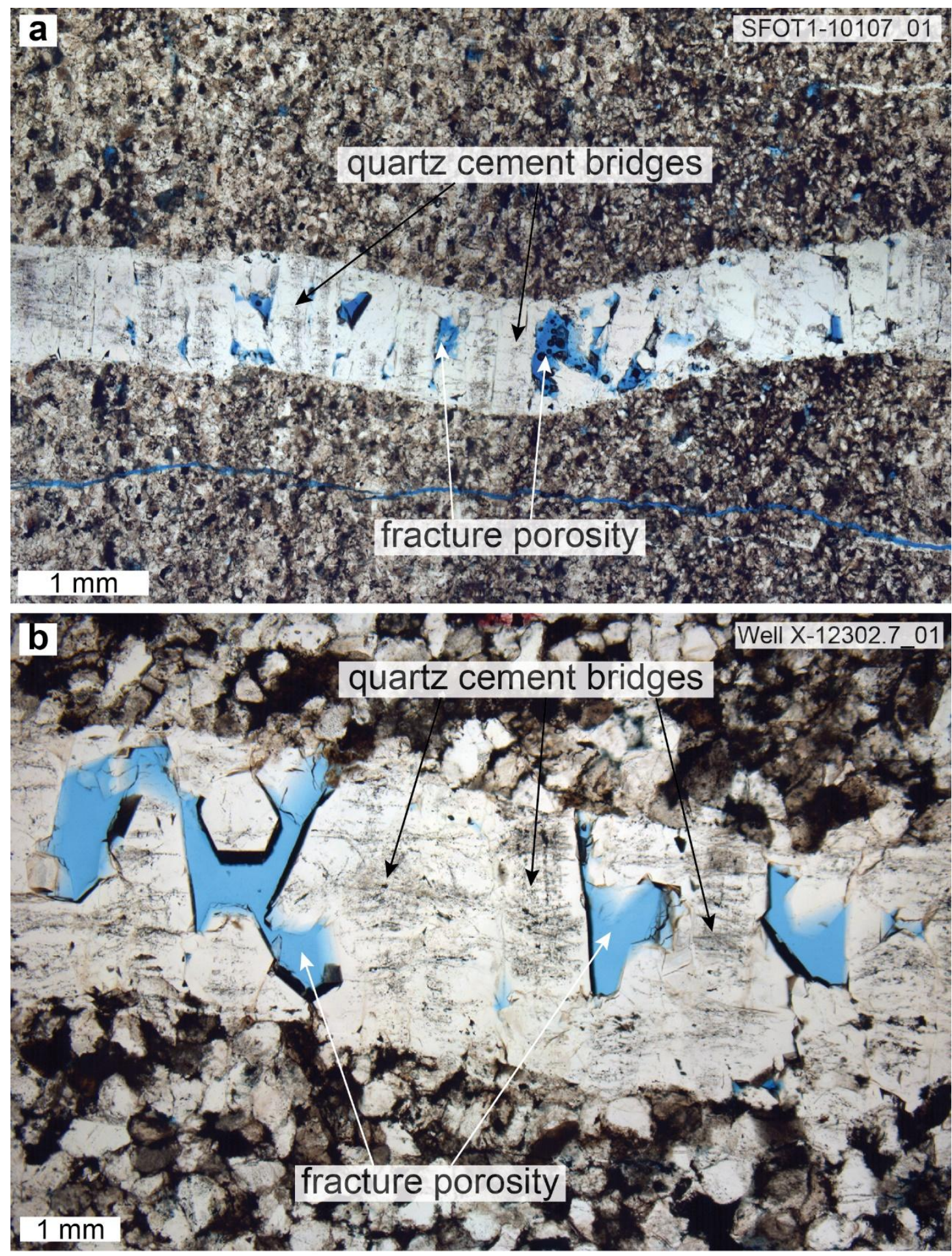

Figure 4.

Fig. 4. (a) Partially filled opening-mode fracture in sandstone showing quartz cement bridges and fracture porosity (blue) in Ashland SFOT well (SFOT1-10107 ft [3080.6 m]), Travis Peak 
Formation, East Texas. (b) Partially filled opening-mode fracture in sandstone showing quartz cement bridges and fracture porosity in well X, Iles Formation, Piceance Basin, Colorado. Bridges described in detail in this study are from these fractures, in the vicinity of the shown bridges. 


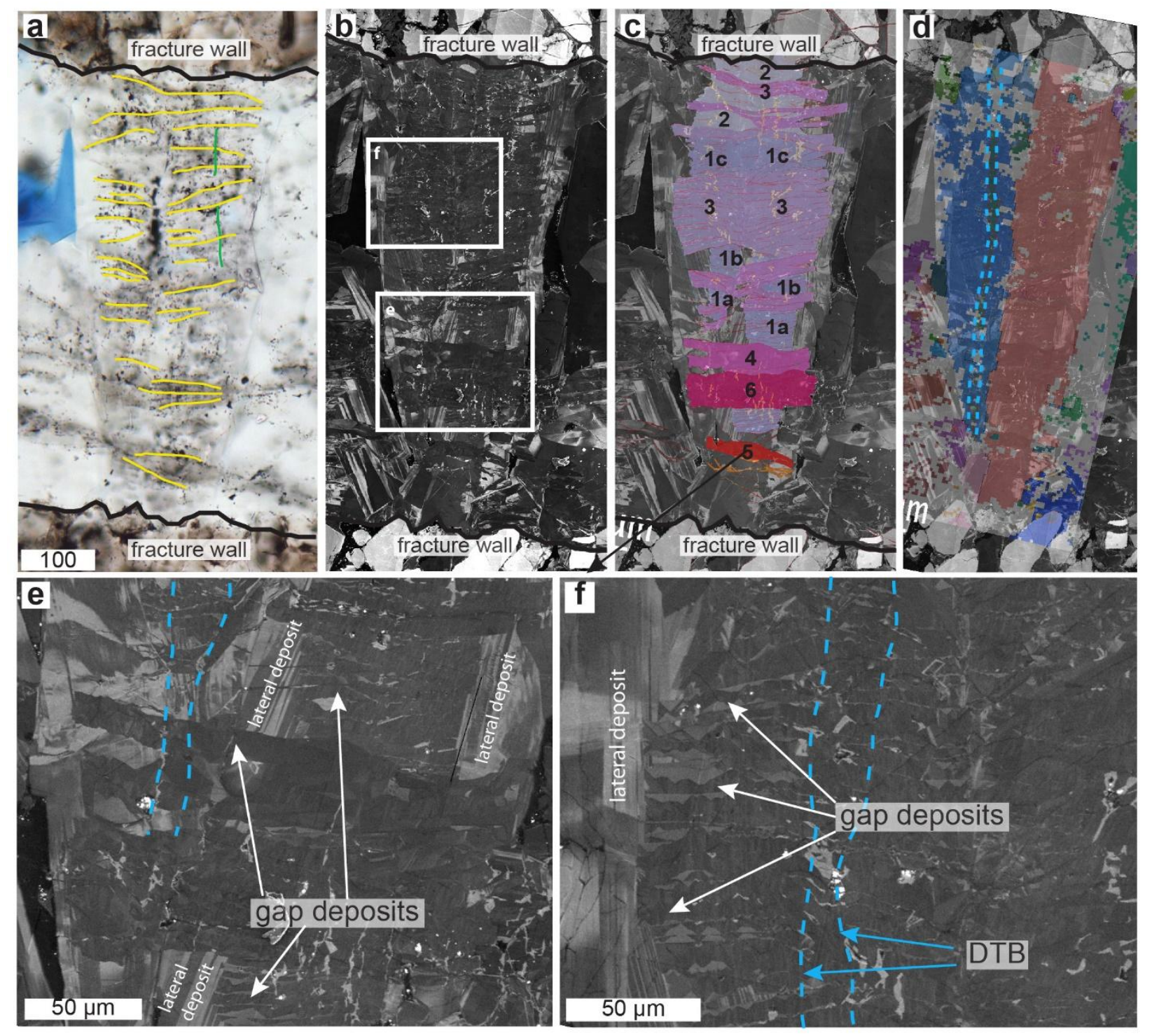

Figure 5.

Fig. 5. Quartz cement bridges in sample SFOT1-10107_B2-3, East Texas, imaged with transmitted light (a), SEM-CL (b-f), and EBSD (d); (a) The core gap deposit zone of quartz cements is decorated by fracture-wall parallel trails of fluid inclusions (highlighted by yellow lines); (b-c) crack-seal cement gap deposits revealed by SEM-CL images; (c) Crosscutting relations and relative length of gap deposits indicates relative timing of opening increments (1a-c shows continuous segments separated by younger gap deposits); (d) EBSD image superimposed 
on SEM-CL image reveals crystal boundaries and Dauphiné twin boundaries (DTB - blue dashed lines) (e) area highlighted in Figure 5b showing relative length of gap deposits. Blue dashed lines show DTB superimposed on a SEM-CL image based on (d); (f) area highlighted in Figure 5b showing relative length of gap deposits and crosscutting relations between gap deposits and lateral deposits. Blue dashed lines show DTB superimposed on a SEM-CL image based on (d). 


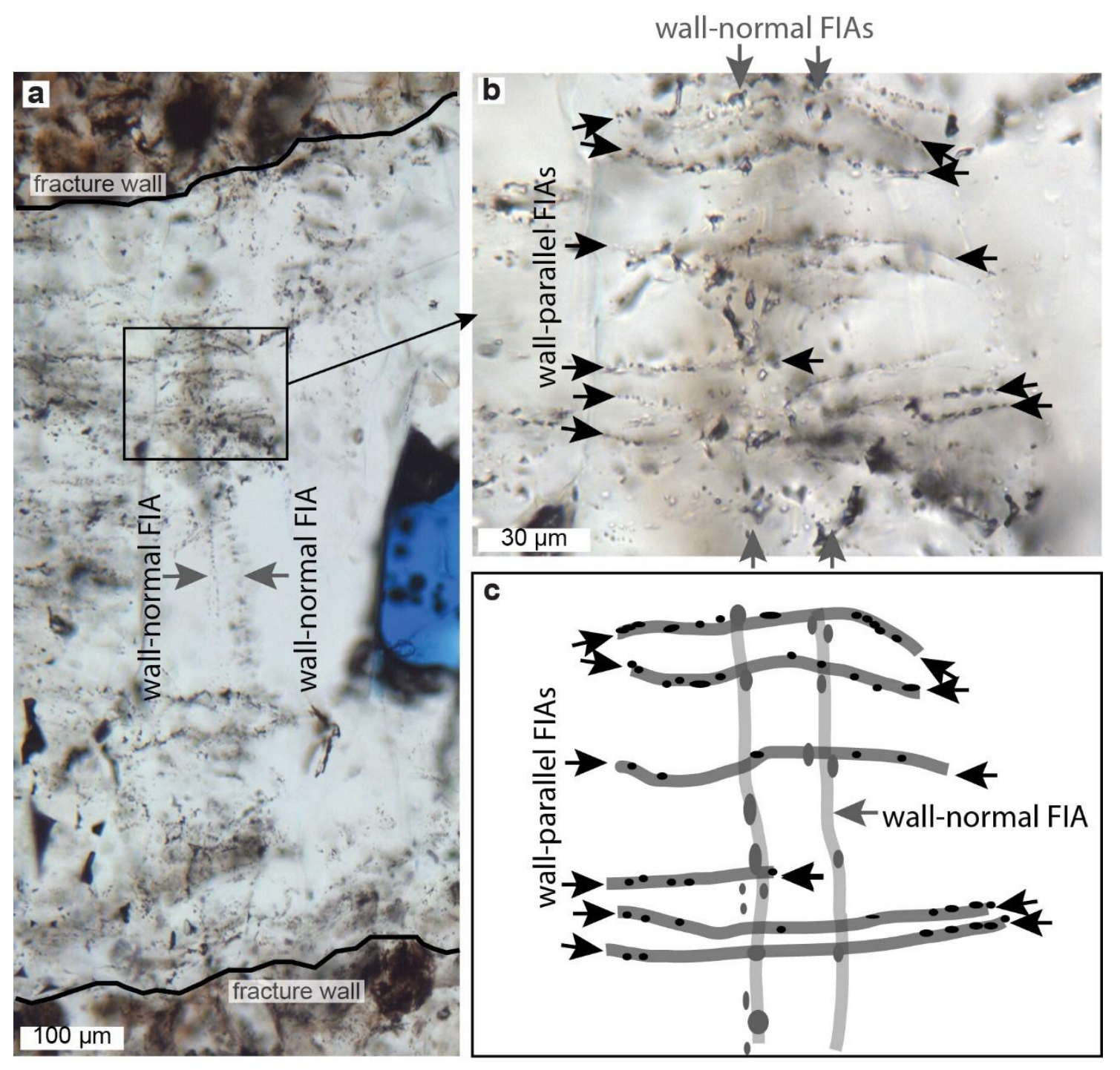

Figure 6.

Fig. 6. Fluid inclusion assemblages (FIAs) trending left-to-right on images (a, b), parallel to fracture wall (a), trapped within gap deposits (not visible in this transmitted light image), and along DTB, trending top-to-bottom of the images $(a, b)$, in quartz cement bridge SFOT110106.85_B9, East Texas Basin. Note large size and irregular shape of fluid inclusions in the wall-normal configuration (b); Image (c) is a sketch highlighting the two different sets of FIAs. 



Figure 7.

Fig. 7. Quartz cement bridge SFOT1-10106.85_B8 from East Texas, imaged with transmitted light (a), SEM CL (b-f), and EBSD (d); (a) The gap deposit zone of quartz cements is decorated by fracture-wall parallel trails of fluid inclusions (highlighted by yellow lines); (b) gap deposits revealed by SEM-CL images; (c) crosscutting relations and relative length of gap deposits 
indicates relative timing of opening increments; (d) EBSD image superimposed on the SEM-CL image reveals crystal boundaries and Dauphiné twin boundaries (DTB - blue dashed lines); (e) area highlighted in Figure $7 \mathrm{~b}$ showing relative length of gap deposits and crosscutting relations between gap and lateral deposits; also shown are two DTB highlighted by the transition from lighter-to-darker luminescence, and to darker-to-lighter luminescence, respectively, from left to right, pointed out by white arrows. High angle sharp line pointed by gray arrows is an artifact from image mosaicking; (f) same area as in (e), but twin boundaries are superimposed with blue dashed lines based on image (d). 




Figure 8.

Fig. 8. Electron backscattered diffraction (EBSD) image of quartz cement bridges in fracture SFOT1-10106.85, East Texas Basin. Pixel size is $5 \times 5 \mu \mathrm{m}$. DTBs are marked by thin red lines. Irregularly shaped patches of twinned domains are usually present in sections that are cut at a high angle to the c-axis (green bridges to the right); bridges cut at a low angle -subparallel- to 
the c-axis tend to have straight, twin boundaries that are parallel to quartz c-axis (pink and dark orange, and blue and green bridges to the left and middle). Blue arrows (DTB no FIA) point to straight DTBs that have no associated FIAs. 

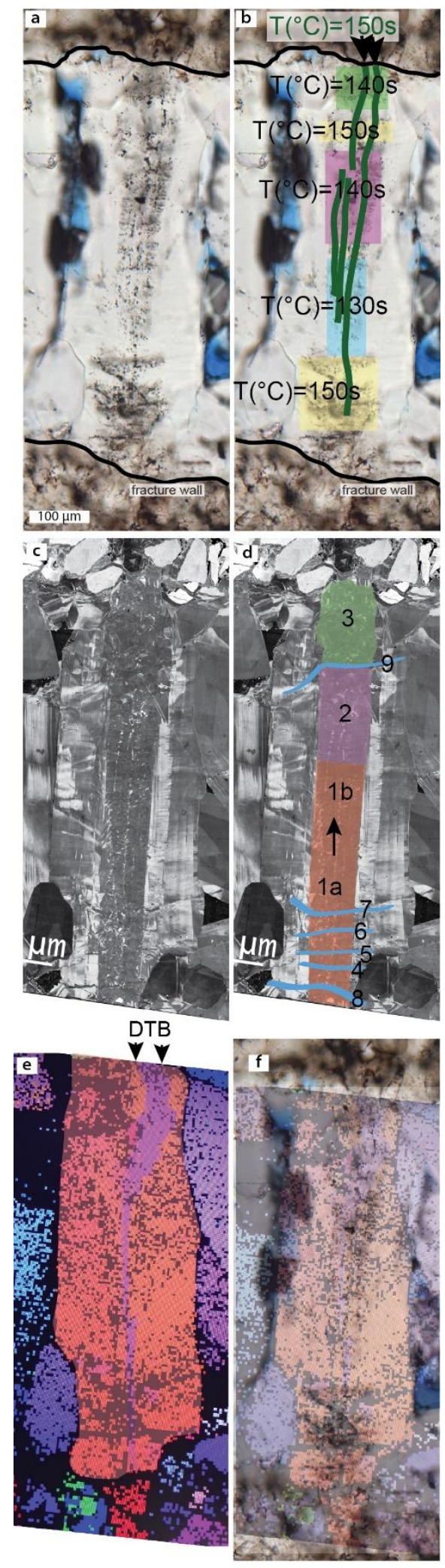

Figure 9. 
Fig. 9. Quartz cement bridge SFOT1-10106.85_B1, East Texas, under transmitted light (TL), SEM-CL, and EBSD images; Fracture walls are at right angles to long dimension of images in all cases; (a) Transmitted light image. (b) Core zone of crack-seal texture color-coded for inclusion temperature in gap deposits with temperature range indicated. Green vertical lines mark fracture-wall-normal FIA alignment with temperature range indicated. Blue indicates epoxy-filled porosity. (c) SEM-CL image. (d) Highlighted gap deposits and interpreted relative timing of increments. (e) EBSD image, showing crystal boundaries and DTBs. (f) Superimposed transmitted light and EBSD images showing the coincidence of wall-normal FIAs and DTBs. 



Figure 10.

Fig. 10. Bright-luminescent halos around fluid inclusions trapped in wall-normal FIAs and along DTBs (arrows). Travis Peak Formation quartz bridge SFOT1-10107-B2 (a) and SFOT110106.85-B9 (b), East Texas. 


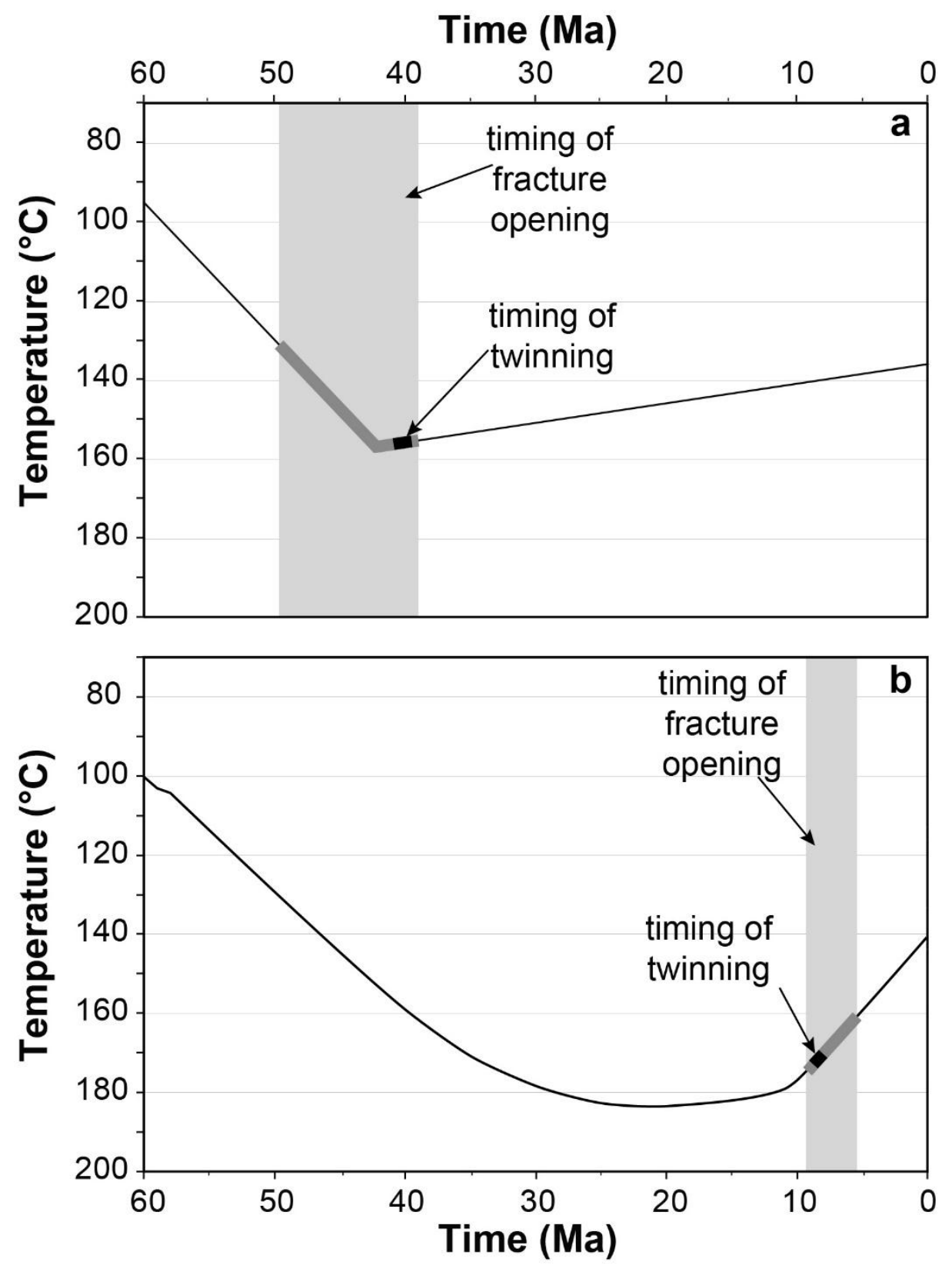

Figure 11.

Fig. 11. Timing of fracture opening and cementation, and Dauphiné twinning of cement bridges in sandstones; (a) twinning in Travis Peak Formation, East Texas occurred at 40 Ma (thermal 
history curve after Becker et al., 2010); (b) twinning in Iles Formation, Piceance Basin, Colorado occurred at $\sim 8 \mathrm{Ma}$ (thermal evolution curve after Fall et al., 2015). 


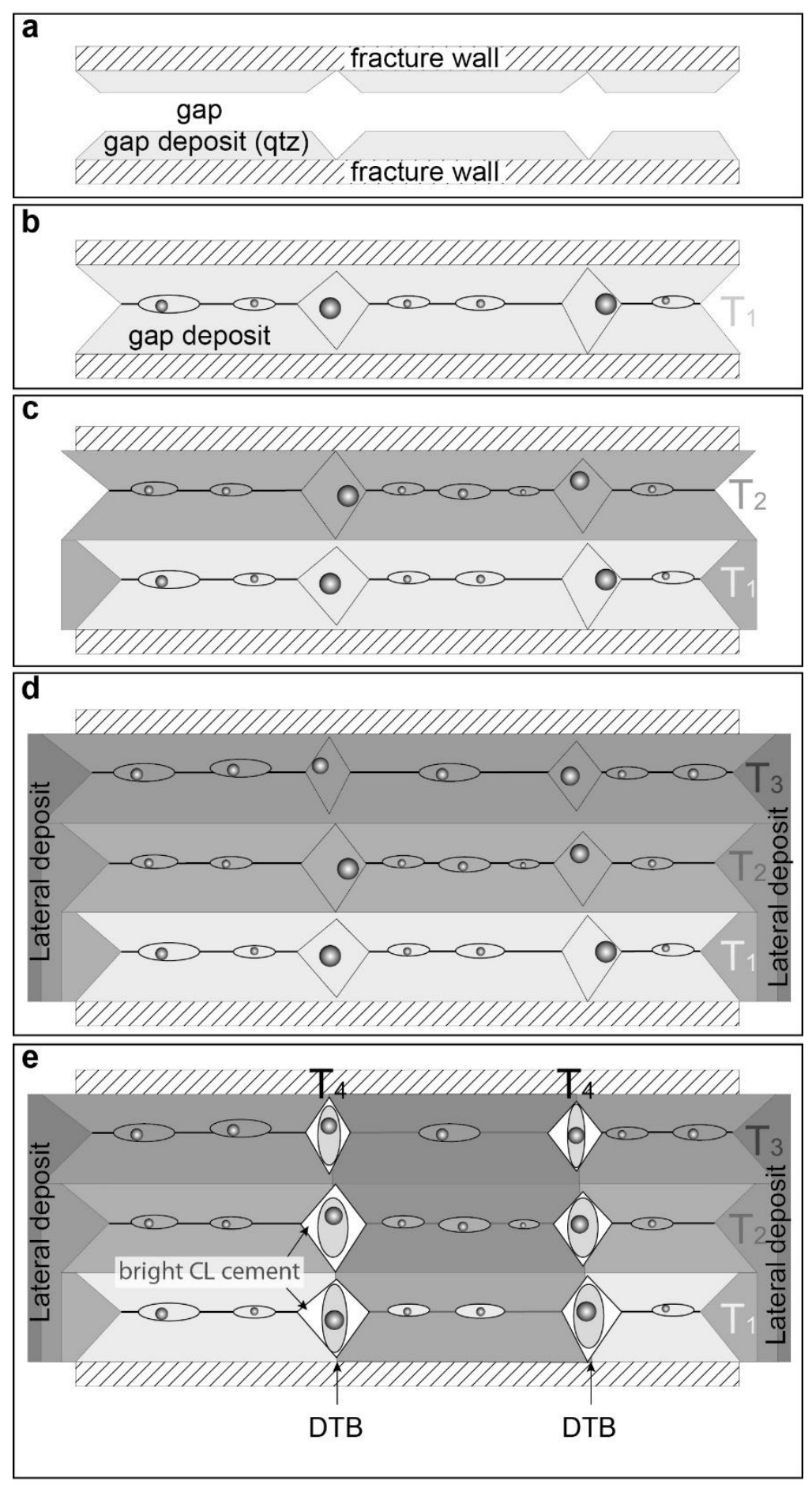

Figure 12.

Fig. 12. Conceptual model for fracturing, gap deposit precipitation, trapping of fluid inclusions, and formation of Dauphiné twins; (a) Fracture forms, and quartz cement precipitates 
synkinematically. Crystal defects or contaminants form crystal phase boundaries and reentrants in the gap deposit; (b) fluid inclusions are trapped along the median line of the gap deposit, recording $T_{1}$ thermal event; (c) subsequent fracture and gap deposit forms recording $T_{2}$ thermal event;the reentrants align as the gap deposit is crystallographically continuous, aligning large fluid inclusions; (d) crack-seal fracture continues to form and cement, recording $\mathrm{T}_{3}$ thermal event; (e) fracture relaxation generates stress on the fracture wall-normal to quartz bridges, fracturing the weak cement between the aligned large fluid inclusions and twinning the quartz along the wall-normal FIAs. Bright-luminescent cement is deposited around large inclusions precipitated from fluid entering the large inclusions at a new P-T $\left(\mathrm{T}_{4}\right)$ condition relative to the ones during gap deposit formation. 


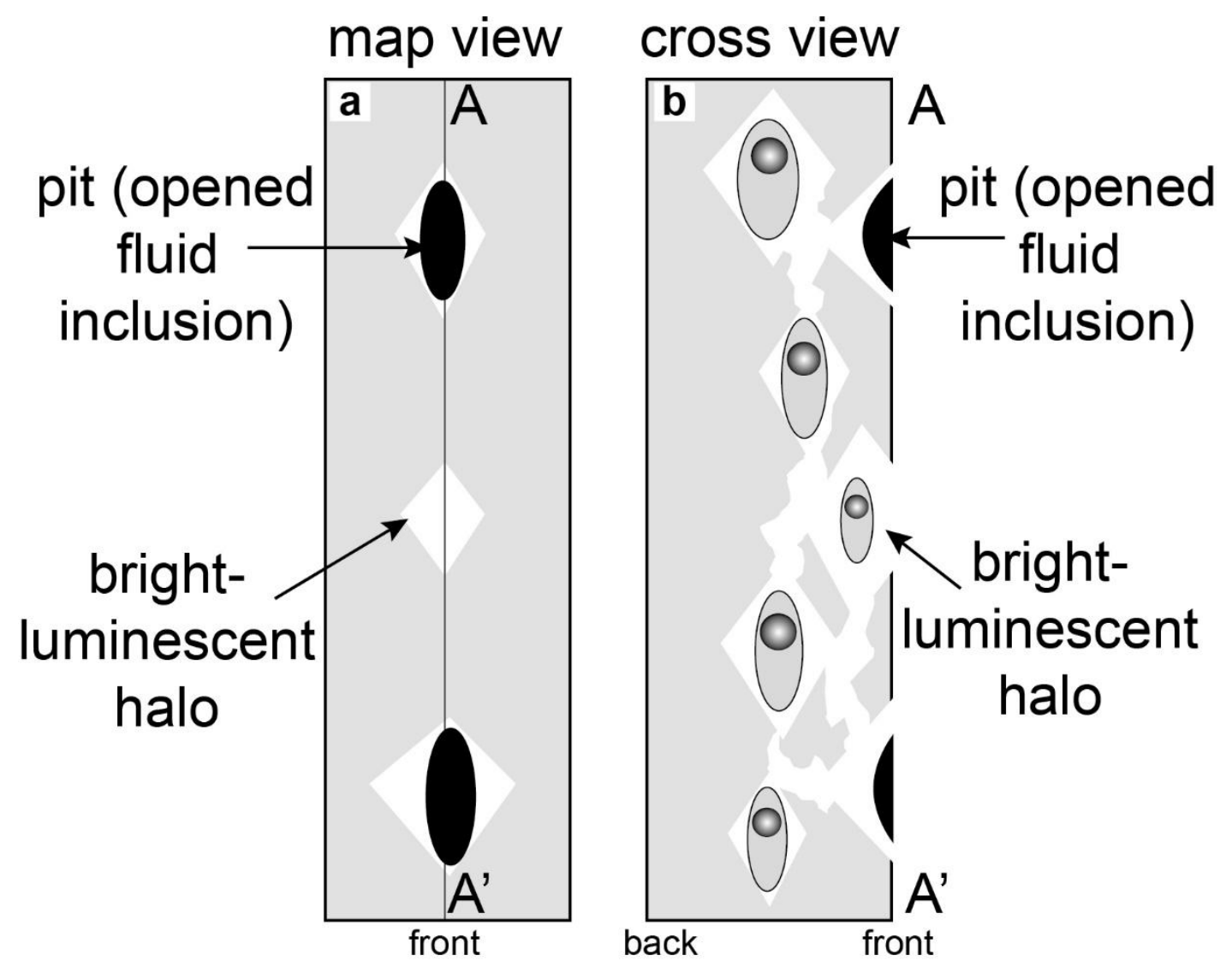

Figure 13.

Fig. 13. Sketch of possible connection of the bright-luminescent halos around fracture wallnormal FIAs, as suggested by some connected halos in SEM-CL images such as those in Figure 10; (a) map view of thin sections with bright CL cement punctuating the thin section surface; (b) cross section view along line A-A' in (a), showing the bright CL cemented inclusions interconnected beneath the surface of the thin section. Black patches represent surface pits formed by opened fluid inclusions during sample polishing. 